\title{
Clinical versus ultrasonographic fetal weight estimation and its correlation with actual birth weight
}

\author{
Ashwini Ingale, Shweta Avinash Khade*, Sneha Shirodkar
}

Department of Obstetrics and Gynecology, BYL TNMC, Mumbai Central, Maharashtra, India

Received: 07 December 2018

Accepted: 07 January 2019

\section{*Correspondence:}

Dr. Shweta Avinash Khade,

E-mail: drshwetam2009@gmail.com

Copyright: (C) the author(s), publisher and licensee Medip Academy. This is an open-access article distributed under the terms of the Creative Commons Attribution Non-Commercial License, which permits unrestricted non-commercial use, distribution, and reproduction in any medium, provided the original work is properly cited.

\begin{abstract}
Background: This is a prospective study was conducted at Obstetrics and Gynecology department, tertiary care Hospital, to compare the accuracy of clinical and ultrasonographic estimation of fetal weight at term with actual birth weight.

Methods: The present study is a prospective comparative study of fetal weight estimation in Antenatal women with term gestation (37week to 42 week of gestation) singleton pregnancy with vertex presentation, who had gestational age confirmed by dates and ultrasound scanning of $<22$ weeks admitted in tertiary care center from March 2016 to November 2016. Patients with Polyhydramnios, oligohydramnios, Antepartum hemorrhage, Congenital anomalies of fetus, Obese (Body mass index $>30$ kilogram $/$ meter $^{2}$ ) are excluded from the study. Estimation of fetal weight is done by clinical method and ultrasonography. Birth weight after delivery was recorded in grams by electronic weighing machine and tabulated.

Results: Clinical as well as ultrasonography estimates observed to be strongly correlate with actual birth weight. Both the methods had more sensitivity in birth weight range $2500-4000 \mathrm{gm}$ than $<2500 \mathrm{~g}$ and $>4000 \mathrm{~g}$. The overall mean absolute percentage error of the clinical method (7.2 \pm 7.7$)$ was smaller than that of the sonographic method (16.2 \pm 11.1$)$. In low birth-weight $(<2,500 \mathrm{~g})$ group, mean absolute percentage error was $9.0 \pm 11.3$ with USG and same with clinical was $11.7 \pm 9.0$. No statistically significant difference was observed.

Conclusions: The present study concludes that clinical estimation of birth-weight is as accurate as routine ultrasonographic estimation.Clinical palpation should be considered as diagnostic tool for FWE and is equally reliable even when done by trained medical person. It is cheap and easy to teach. The need is to practically apply this method in obstetrics and guide the management decisions.
\end{abstract}

Keywords: Birth weight, Clinical method, Fetal weight, Ultrasonography

\section{INTRODUCTION}

Accurate estimation of fetal weight is of paramount importance in the management of labour and delivery. During the last decade, estimated fetal weight has been incorporated into the standard routine antepartum evaluation of high-risk pregnancies and deliveries. For instance, management of diabetic pregnancy, vaginal birth after a previous caesarean section, and intrapartum management of fetuses presenting by the breech will be greatly influenced by estimated fetal weight. ${ }^{1,2}$

Also, when dealing with anticipated preterm delivery, perinatal counselling on likelyhood of survival, the intervention undertaken to postpone preterm delivery, optimal route of delivery, or the level of hospital where delivery should occur may be based wholly or in part on the estimation of expected birth-weight. Categorization of 
fetal weight into either small or large for gestational age may lead to timed obstetric interventions that collectively represent significant departure from routine antenatal care. $^{3-5}$ Large portion of this problem is related to birthweight which remains the single most important parameter that determines neonatal survival. ${ }^{6,7}$

It is estimated that $16 \%$ of live born infants have low birth-weight, a condition associated with high perinatal morbidity and mortality. Fetal macrosomia is associated with maternal morbidity, shoulder dystocia, birth asphyxia, and birth trauma. ${ }^{8}$

An incidence of $1.6 \%$ of macrosomia was quoted in Obafemi Awolowo University Teaching Hospital Complex, IleIfe, in 1991, while $4.9 \%$ was reported in 1983 to 1985 series in the Lagos university teaching hospital. ${ }^{9}$

It has been suggested that accurate estimation of fetal weight would help in successful management of labour and care of the new born in the neonatal period and help avoidance of complications associated with fetal macrosomia in low-birth-weight babies, thereby decreasing perinatal morbidity and mortality. ${ }^{10}$

The two main methods for predicting birth-weight in current obstetrics are: clinical techniques based on abdominal palpation of foetal parts and calculations based on fundal height.

Sonographic measures of skeletal fetal parts which are then inserted into regression equations to derive estimated fetal weight.

Although some investigators consider sonographic estimates to be superior to clinical estimates, others, in comparing both the techniques concurrently, conclude that they confer similar levels of accuracy. ${ }^{10}$ The available techniques can be broadly classified as:

\section{Clinical methods}

Tactile assessment of fetal size, e.g. Leopold's maneuver; clinical risk factor; maternal self-estimated fetal weight; and prediction of equations of birth-weight.

\section{Imaging methods}

Ultrasonography and magnetic resonance imaging. Aim of this experiment is to compare accuracy of clinical and ultrasonographic estimation of fetal weight and its correlation with actual birth weight.

The objectives of this study are to compare clinically estimated fetal weight with actual birth weight; to compare ultrasonographic estimated fetal weight with actual birth weight; to correlate clinically estimated fetal weight with actual birth weight; to correlate ultrasonographic estimated fetal weight with actual birth weight and to correlate clinically estimated fetal weight with ultrasonographic weight and then with actual birth weight.

\section{METHODS}

It was a prospective comparative study, duration was March 2016 to November 2016. Study population included antenatal women who were admitted in labour room of Obstetrics and Gynecology department, tertiary care hospital, Mumbai for safe confinement.

\section{Inclusion criteria}

- All reproductive age group women with term gestation (37 weeks to 42 weeks of third trimester) singleton pregnancy with vertex presentation, who had gestational age confirmed by dates and ultrasound scanning of $<22$ weeks.

\section{Exclusion criteria}

- Polyhydramnios, oligohydramnios

- Antepartum hemorrhage

- Congenital anomalies of fetus

- Obese (Body mass index $>30$ kilogram $/ \mathrm{meter}^{2}$ ).

The data was collected from study population taken as per inclusion and exclusion criteria using prepared proforma meeting the objectives of study by means of estimation of fetal weight by:

\section{Clinical method}

Fundal height was measured using a non-elastic tape from the highest point on the uterine fundus to the midpoint of the upper border of the symphysis pubis. The thumb was used to hold the tape while attempting to reach the upper border of the symphysis pubis. Measurement was made 3 times using the tape reverseside up to avoid any bias. The mean of the 3 readings was then obtained to the nearest centimetre.

\section{Dare's method}

Birth weight $($ Grams $)=$ Fundal height $(\mathrm{cm}) \times$ Abdominal girth $(\mathrm{cm})$. After recording clinically estimated fetal weight, patient was sent for obstetric ultrasonography. Thus, the study team members were blinded to the details of sonographic fetal weight. The sonologist was not having any access to patient's records containing clinical measurements. Thus, the sonologist was blinded to the details of clinical fetal weight estimation.

\section{Ultrasonographic method}

Hadlock's formula is a formula for estimating fetal weight that is devised by Hadlock on the basis of biparietal diameter (BPD), head circumference (HC), abdominal circumference (AC), and femoral length (FL) 
Hadlock 3: $\log _{10} \mathrm{BW}=1.335-0.000034 \quad$ (ACxFL) + $0.00316 \times(\mathrm{BPD})+0.0045(\mathrm{AC})+0.01623(\mathrm{FL})$. The ultrasound machine used is real-time with abdominal sector $3.5 \mathrm{MHz}$ transducer.

Birth weight after delivery was recorded in grams by electronic weighing machine and tabulated.

\section{Ultrasonographic images for fetal biometry}

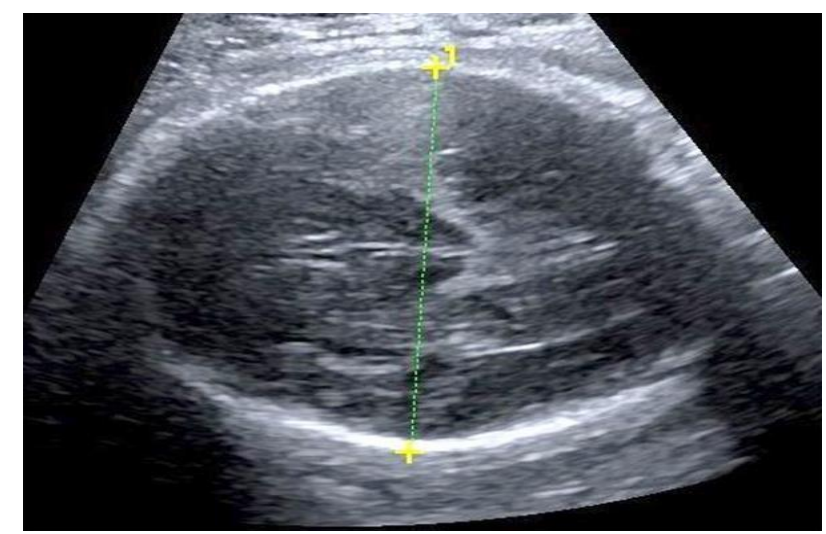

Figure 1: Measurement of biparietal diameter (BPD).

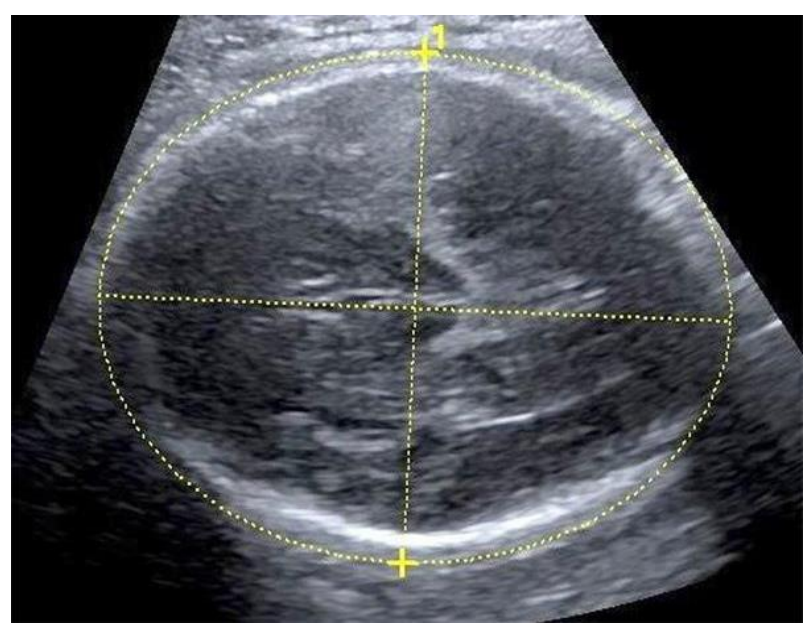

Figure 2: Measurement of head circumference (HC).

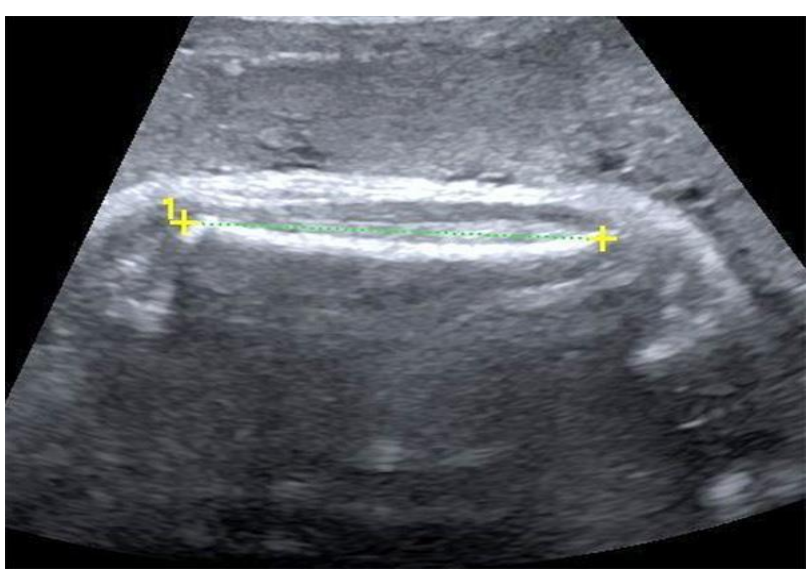

Figure 3: Measurement of femur length (FL).

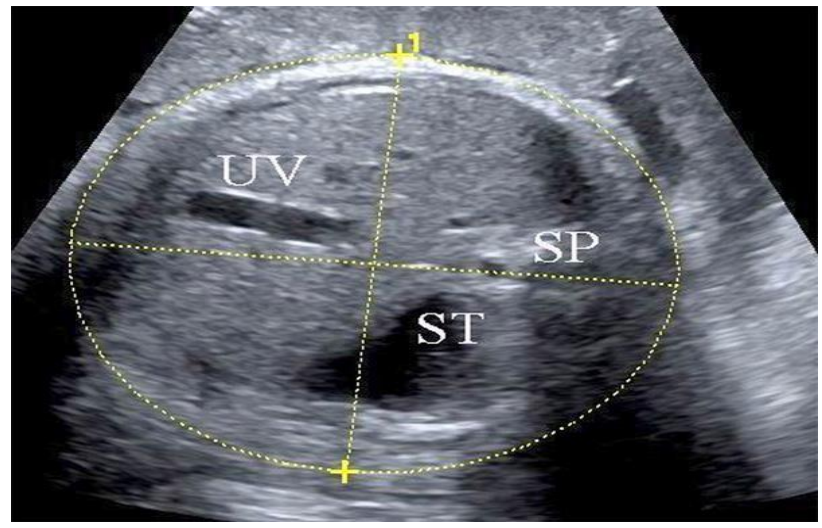

SP: Spine, ST: Stomach, UV: Umbilical Vein.

Figure 4: Standard abdominal sector and standard measurement of $\mathrm{AC}$ (AC1).

100 Antenatal women as per inclusion and exclusion criteria. Sample size was calculated as per data in article: "Determination of accuracy of fetal weight using ultrasound and clinical fetal weight estimations in Calabar South, South Nigeria" published in International scholarly research notices taking into consideration correlation coefficient of clinical and ultrasonographic fetal weight estimation with actual birth weight of baby, which was 0.740 and 0.847 respectively, minimum sample size found to be 12 and 8 respectively at $80 \%$ power and $95 \%$ confidence interval.

Considering following factors sample size of 100 is taken: admissions at our labour room, tertiary care hospital, Mumbai: approximately 300 deliveries per month take place. Study duration: in mentioned study duration it was possible to take the sample size of 100 for better study results.

Hence even though the minimum sample size for study found to be 12 and 8 considering correlation coefficient of clinical and ultrasonographic fetal weight estimation with actual birth weight of baby respectively, sample size taken as 100 .

\section{Statistical analysis}

After data collection, data entry has been done with excel and analysis has been done with proper statistical software.

\section{Descriptive statistics}

For continuous variable range, mean and standard deviation were calculated and for categorical variables proportion and percentage were obtained.

\section{Bi-variate analysis}

To know the association between dependent and independent variable chi-square applied accordingly. 
Comparison of parameter has been obtained with help of unpaired ' $t$ ' test. Correlation among various measurement techniques have been done with help of Pearson's correlation coefficient.

\section{RESULTS}

Table 1 shows that almost $88.0 \%$ participant's pregnancy have gestational age more than 36weeks by recent ultrasonography. Mean gestational age was 37.5 weeks with 1.52 weeks SD.

Table 1: Gestational age among study participants by recent ultrasonography $(\mathrm{n}=\mathbf{1 0 0})$.

\begin{tabular}{|l|l|l|}
\hline Gestational age (in week) & Number & Percentage \\
\hline $34-36$ & 12 & 12.0 \\
\hline$>36$ & 88 & 88.0 \\
\hline $\begin{array}{l}\text { Mean gestational age } \\
\text { (Mean } \pm \text { SD) }\end{array}$ & $37.5 \pm 1.52$ & \\
\hline
\end{tabular}

Table 2 shows that $49 \%$ participants were belonged to group of 30 to $35 \mathrm{~cm}$ fundal height and $44 \%$ belonged to 25 to $30 \mathrm{~cm}$ fundal height. Mean fundal height was 31.41 cm with 2.42 SD.

Table 2: Fundal height distribution among study participants $(n=100)$.

\begin{tabular}{|l|l|l|}
\hline Fundal height $(\mathrm{cm})$ & Number & Percentage \\
\hline $25-30$ & 44 & 44.0 \\
\hline $30-35$ & 49 & 49.0 \\
\hline$\geq 35$ & 7 & 7.0 \\
\hline $\begin{array}{l}\text { Mean height } \\
\text { (Mean } \pm \text { SD) }\end{array}$ & $31.41 \pm 2.42$ & \\
\hline
\end{tabular}

Table 3 shows that $45 \%$ participants were belonged to group of 80 to $90 \mathrm{~cm}$ abdominal girth and $43 \%$ belonged to 90 to $100 \mathrm{~cm}$ fundal height. Mean abdominal girth was $92.5 \mathrm{~cm}$ with $6.41 \mathrm{SD}$.

Table 3: Abdominal girth distribution among study participants $(n=100)$.

\begin{tabular}{|l|l|l|}
\hline Abdominal girth $(\mathrm{cm})$ & Number & Percentage \\
\hline $80-90$ & 45 & 45.0 \\
\hline $90-100$ & 43 & 43.0 \\
\hline $100-110$ & 12 & 12.0 \\
\hline $\begin{array}{l}\text { Mean height } \\
(\text { Mean } \pm \text { SD) }\end{array}$ & $92.5 \pm 6.41$ & \\
\hline
\end{tabular}

Table 4 shows fetal birth weight estimated by ultrasonography. Results shows that $88 \%$ fetus were belonged to birth weight group of 2500 to 4000 grams, where $7 \%$ have less than 2500gram and 5\% have more than $4000 \mathrm{gm}$ birth weight. Mean birth weight measure by USG was 3203.66gm with 497.05gm SD.
Table 4: Fetal weight by ultrasonography $(n=100)$.

\begin{tabular}{|l|l|l|}
\hline Fetal weight $(\mathrm{g})$ & Number & Percentage \\
\hline$<2500$ & 7 & 7.0 \\
\hline $2500-4000$ & 88 & 88.0 \\
\hline$>4000$ & 5 & 5.0 \\
\hline $\begin{array}{l}\text { Mean weight } \\
\text { (Mean } \pm \text { SD) }\end{array}$ & $3203.66 \pm 497.05$ & \\
\hline
\end{tabular}

Table 5 shows birth weight estimated by clinical examination. Results shows that $87 \%$ fetal were belonged to birth weight group of 2500 to 4000 grams, where $13 \%$ have less than 2500gram.

Mean birth weight measured by clinical examination was 2916.6 gm with $399.15 \mathrm{gm}$ SD.

Table 5: Fetal weight by clinical examination $(n=100)$.

\begin{tabular}{|l|l|l|}
\hline Fetal weight $(\mathrm{g})$ & Number & Percentage \\
\hline$<2500$ & 13 & 13.0 \\
\hline $2500-4000$ & 87 & 87.0 \\
\hline$>4000$ & 0 & 0.0 \\
\hline $\begin{array}{l}\text { Mean weight } \\
(\text { Mean } \pm \text { SD) }\end{array}$ & $2916.6 \pm 399.15$ & \\
\hline
\end{tabular}

Table 6 shows actual birth weight measured immediate after delivery.

Results shows that $70 \%$ babies were belonged to birth weight group of 2500 to 4000 grams, where $25 \%$ have less than 2500gram and 5\% have more than $4000 \mathrm{gm}$ birth weight. Actual mean birth weight was $2831.79 \mathrm{gm}$ with 497.05gm SD.

Table 6: Actual birth weight of infant $(n=100)$.

\begin{tabular}{|l|l|l|}
\hline Fetal weight $(\mathrm{g})$ & Number & Percentage \\
\hline$<2500$ & 25 & 25.0 \\
\hline $2500-4000$ & 70 & 70.0 \\
\hline$>4000$ & 5 & 5.0 \\
\hline Mean weight & 2831.79 & \\
(Mean \pm SD) & \pm 497.05 & \\
\hline
\end{tabular}

Table 7 shows that mean birth weight estimated by clinical examination was $2916.6 \mathrm{gm}$ with $399.15 \mathrm{gm}$ SD is higher than actual mean birth weight which was 2831.79 gm with 515.79gm SD.

Difference between mean birth weight estimated by clinical examination and mean actual birth weight was statistically significant $(\mathrm{p}<0.05)$.

There was a statistically significant strong correlation between above two methods for birth weight observation $(\mathrm{r}=0.87, \mathrm{p}<0.0001)$. 
Table 7: Correlation of estimated birth weight by clinical examination with actual birth weight $(\mathrm{n}=100)$.

\begin{tabular}{|c|c|c|c|}
\hline \multicolumn{2}{|l|}{ Mean birth weight } & \multirow{2}{*}{ P value* } & \multirow{2}{*}{ Correlation coefficient } \\
\hline Clinical examination & Actual weight & & \\
\hline $2916.6 \pm 399.15$ & $2831.79 \pm 515.79$ & $<0.001$ & $0.87 * *$ \\
\hline
\end{tabular}

Table 8: Correlation of estimated birth weight by ultra-sonography with actual birth weight $(\mathrm{n}=100)$.

\begin{tabular}{|c|c|c|c|}
\hline \multicolumn{2}{|c|}{ Mean birth weight } & \multirow{2}{*}{ P value* } & \multirow{2}{*}{ Correlation coefficient } \\
\hline USG & Actual weight & & \\
\hline $3203.66 \pm 497.05$ & $2831.79 \pm 515.79$ & $<0.001$ & $0.76^{* *}$ \\
\hline
\end{tabular}

Table 8 shows that mean birth weight estimated by USG was 3203.66 gm with $497.05 \mathrm{gm}$ SD is higher than actual mean birth weight which was 2831.79 gm with 515.79 gm SD.

Difference between mean birth weight estimated by ultrasonography and mean actual birth weight was statistically significant $(\mathrm{p}<0.05)$. There was a statistically significant strong correlation between above two methods for birth weight observation $(r=0.76, \mathrm{p}<0.05)$.

Table 9 shows that out of total low birth weight $(<2500$ gm) delivery, $76 \%$ delivery done through vaginal delivery and $24 \%$ delivery done by LSCS, where out of total normal birth weight delivery, $58.6 \%$ delivery done by vaginal delivery and $41.4 \%$ done by LSCS. But this association found statistically insignificant $(\mathrm{p}>0.05)$.
Table 9: Association between mode of delivery and actual birth weight among study participants $(n=100)$.

\begin{tabular}{|c|c|c|c|c|}
\hline \multirow{2}{*}{$\begin{array}{l}\text { Mode of } \\
\text { delivery }\end{array}$} & \multicolumn{3}{|c|}{ Actual birth weight } & \multirow[b]{2}{*}{ p value $*$} \\
\hline & $\begin{array}{l}<2500 \\
(\%)\end{array}$ & $\begin{array}{l}2500- \\
4000(\%)\end{array}$ & $\begin{array}{l}>4000 \\
(\%)\end{array}$ & \\
\hline Vaginal & $19(76.0)$ & $41(58.6)$ & $3(60.0)$ & \multirow{2}{*}{0.298} \\
\hline LSCS & $6(24.0)$ & $29(41.4)$ & $2(40.0)$ & \\
\hline
\end{tabular}

Table 10 shows that out of total low birth weight $(<2500$ gm) delivery, $32 \%$ study participants have a history of risk factor and out of total normal birth weight (2500 to $4000 \mathrm{gm}$ ) delivery, $17.1 \%$ study participants have history of risk factor. This association found statistically significant $(\mathrm{p}<0.05)$.

Table 10: Association between risk factor and actual birth weight among study participants (n=100).

\begin{tabular}{|c|c|c|c|c|}
\hline \multirow{2}{*}{ Risk factor } & \multicolumn{3}{|c|}{ Actual birth weight } & \multirow[b]{2}{*}{ p value $*$} \\
\hline & $<2500(\%)$ & $2500-4000(\%)$ & $>4000(\%)$ & \\
\hline Absent & $17(68.0)$ & $58(82.9)$ & $2(40.0)$ & \multirow{2}{*}{0.041} \\
\hline Present & $8(32.0)$ & $12(17.1)$ & $3(60.0)$ & \\
\hline
\end{tabular}

Table 11: Association between fundal height and actual birth weight among study participants $(n=100)$.

\begin{tabular}{|c|c|c|c|c|}
\hline \multirow{2}{*}{$\begin{array}{l}\text { Fundal } \\
\text { height } \\
\text { (in cm) }\end{array}$} & \multicolumn{3}{|c|}{ Actual birth weight } & \multirow[b]{2}{*}{$\begin{array}{l}\text { p } \\
\text { value* }\end{array}$} \\
\hline & $\begin{array}{l}<2500 \\
(\%)\end{array}$ & $\begin{array}{l}2500- \\
4000(\%)\end{array}$ & $\begin{array}{l}>4000 \\
(\%)\end{array}$ & \\
\hline $25-30$ & $21(84.0)$ & $23(32.9)$ & $0(0.0)$ & \multirow{3}{*}{0.0001} \\
\hline $30-35$ & $4(16.0)$ & $42(60.0)$ & $3(60.0)$ & \\
\hline$\geq 35$ & $0(0.0)$ & $5(7.1)$ & $2(40.0)$ & \\
\hline
\end{tabular}

* - Chi-square test

Table 11 shows that out of total low birth weight $(<2500$ gm) delivery, $84 \%$ study participants have fundal height 25 to $30 \mathrm{~cm}, 12 \%$ have fundal height 30 to $35 \mathrm{~cm}$ and $4 \%$ have fundal height more than $35 \mathrm{~cm}$.
Out of total normal birth weight (2500 to $4000 \mathrm{~g}$ ) delivery, $32.9 \%$ study participants fundal height 25 to 30 $\mathrm{cm}, 60 \%$ have fundal height 30 to $35 \mathrm{~cm}$ and $7.1 \%$ have fundal height more than $35 \mathrm{~cm}$. This association found statistically significant $(\mathrm{p}<0.05)$.

Table 12 shows that out of total low birth weight $(<2500$ gm) delivery, $88 \%$ study participants have abdominal girth 80 to $90 \mathrm{~cm}, 12 \%$ have AG 90 to $100 \mathrm{~cm}$.

Out of total normal birth weight (2500 to $4000 \mathrm{gm}$ ) delivery, $32.9 \%$ study participants have abdominal girth 80 to $90 \mathrm{~cm}, 55.7 \%$ have AG 90 to $100 \mathrm{~cm}$ and $11.4 \%$ have AG 100 to $110 \mathrm{~cm}$. This association found statistically significant $(\mathrm{p}<0.05)$. 
Table 12: Association between abdominal girth and actual birth weight among study participants $(n=100)$.

\begin{tabular}{|c|c|c|c|c|}
\hline \multirow{2}{*}{$\begin{array}{l}\text { Abdominal } \\
\text { girth (in } \\
\mathrm{cm} \text { ) }\end{array}$} & \multicolumn{3}{|c|}{ Actual birthweight } & \multirow[b]{2}{*}{$\begin{array}{l}\text { p } \\
\text { value* }\end{array}$} \\
\hline & $\begin{array}{l}<2500 \\
(\%)\end{array}$ & $\begin{array}{l}2500- \\
4000(\%)\end{array}$ & $\begin{array}{l}>4000 \\
(\%)\end{array}$ & \\
\hline $80-90$ & $22(88.0)$ & $23(32.9)$ & $0(0.0)$ & \multirow{3}{*}{0.0001} \\
\hline $90-100$ & $3(12.0)$ & $39(55.7)$ & $1(20.0)$ & \\
\hline $100-110$ & $0(0.0)$ & $8(11.4)$ & $4(80.0)$ & \\
\hline
\end{tabular}

Table 13 shows that the accuracy and statistical differences between clinical and ultrasonically-estimated percentage error was almost double in USG than clinical method to estimate birth weight and difference was statistically significant, where in mean percentage error was much lower in USG than clinical method and this difference was also statistically significant.

Table 13: Accuracy and difference between USG and clinical methods $(n=100)$.

\begin{tabular}{|c|c|c|c|}
\hline Birth weight & USG & $\begin{array}{l}\text { Clinical } \\
\text { method }\end{array}$ & p value \\
\hline \multicolumn{4}{|l|}{ Overall } \\
\hline $\begin{array}{l}\text { Mean absolute } \\
\text { percentage error }\end{array}$ & $16.2 \pm 11.1$ & $7.2 \pm 7.7$ & $0.0001 *$ \\
\hline $\begin{array}{l}\text { Mean percentage } \\
\text { error }\end{array}$ & $-14.1 \pm 13.4$ & $-4.2 \pm 9.7$ & $0.0001 * *$ \\
\hline \multicolumn{4}{|l|}{$<2500 \mathrm{~g}$} \\
\hline $\begin{array}{l}\text { Mean absolute } \\
\text { percentage error }\end{array}$ & $9.0 \pm 11.3$ & $11.7 \pm 9.0$ & $0.60 *$ \\
\hline $\begin{array}{l}\text { Mean } \\
\text { percentage error }\end{array}$ & $-5.7 \pm 19.8$ & $-9.8 \pm 11.1$ & $0.62 * *$ \\
\hline \multicolumn{4}{|l|}{$2500-4000 \mathrm{~g}$} \\
\hline $\begin{array}{l}\text { Mean absolute } \\
\text { percentage error }\end{array}$ & $16.5 \pm 11.2$ & $6.6 \pm 7.4$ & $0.001 *$ \\
\hline $\begin{array}{l}\text { Mean } \\
\text { percentage error }\end{array}$ & $-15.4 \pm 12.8$ & $-3.3 \pm 9.3$ & $0.001 * *$ \\
\hline \multicolumn{4}{|l|}{$>4000 \mathrm{~g}$} \\
\hline $\begin{array}{l}\text { Mean absolute } \\
\text { percentage error }\end{array}$ & $8.5 \pm 9.9$ & - & - \\
\hline $\begin{array}{l}\text { Mean } \\
\text { percentage error }\end{array}$ & $-8.5 \pm 9.9$ & - & - \\
\hline
\end{tabular}

In $<2500 \mathrm{~g}$ birth weight group, mean absolute percentage error was higher in clinical method than USG to estimate birth weight but difference was statistically not significant $(\mathrm{p}>0.05)$. Mean percentage error was much lower in clinical method than USG to estimate birth weight but the difference was statistically not significant ( $p>0.05$ ). In 2500-4000gm birth weight group, mean absolute percentage error was almost more than double in USG than clinical method to estimate birth weight and difference was statistically significant $(p<0.05)$, where in mean percentage error was much lower in USG than clinical method and this difference was also statistically significant $(\mathrm{p}<0.05)$.

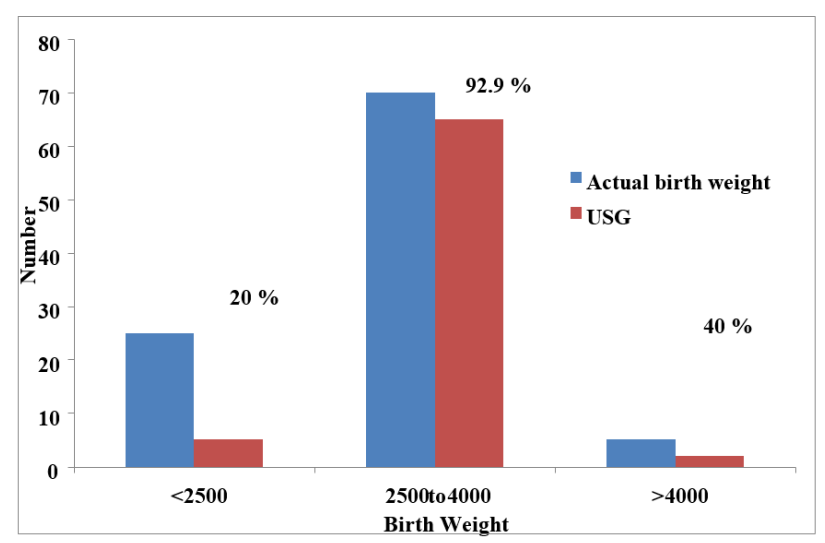

Figure 5: Sensitivity USG to predict birth weight in study population $(n=100)$.

Figure 5 shows that USG has $92.9 \%$ sensitivity to predict normal birth weight, $20.0 \%$ to predict low birth weight and $40.0 \%$ to predict more than 4000 gm birth weight.

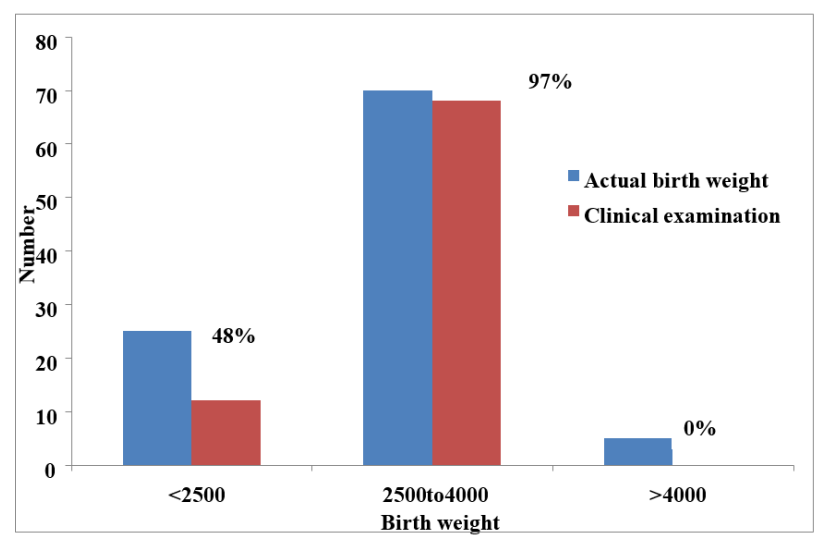

Figure 6: Sensitivity clinical examination to predict birth weight in study population $(n=100)$.

Figure 6 shows that clinical examination has $97.1 \%$ sensitivity to predict normal birth weight, $48.0 \%$ to predict low birth weight and $0.0 \%$ to predict more than 4000 gm birth weight.

\section{DISCUSSION}

Accurate prediction of fetal weight has been of great interest in obstetrics. As fetal weight cannot be measured directly, it must be estimated from fetal and maternal anatomical characteristics. Of the various methods, the most-commonly used are the clinical and ultrasonographic methods. Only a few studies have compared the accuracy of fetal weight by clinical and ultrasonic measurements.

In previous studies, no standardized method was used for clinical estimation, making it subjective, poorly defined, and non-reproducible. The sonographic method is widely used because it is objective and reproducible and involves a well-defined measurement procedure. 
Chauhan et al, in their comparison of accuracy of the two methods, observed no benefit in obtaining a sonographic estimate because its accuracy is no better than that of the clinical method, except there is low birth-weight $(<2,500 \mathrm{~g})$ when ultrasound yields a better prediction. ${ }^{2}$ They, however, concluded that an estimate of birthweight is associated with a wide range of actual birthweight, making obstetric decision based on such prediction to be likely associated with unnecessary intervention. In this study, authors used a standardized method of clinical estimation that had been found previously to correlate well with birth-weight, making it a unit protocol in our center. The Hadlock formula present on the ultrasound machine in our radiology unit was used for ultrasonic estimation since authors who compared the accuracy of conventionally-used formulae suggest that no single formula estimated birthweight more accurately to a significant degree than any other formulae, thus eliminating the bias that authors used only Hadlock formula. ${ }^{3}$ The estimates were obtained independently by two different observers (i.e. attending registrars) in the obstetrics and radiology units in this study, precluding the possibility that one estimate may influence the other. The estimations were also done within 24 hours of delivery to increase the prediction power of each method. Despite the differences in study design, our findings are in consonance with those reported by others that the accuracy of clinical estimation of birth-weight is similar if not better than that of ultrasonic estimation. The studies by Hendrix et al, and Raman et al, showed that clinical estimation was significantly more accurate than sonographic prediction. ${ }^{5,6}$ Watson et al, found no significant difference between the two methods even at extremes of birth-weight at term. ${ }^{7}$ This is in consonance with what several investigators have shown that the clinical method is best for estimating fetal weight in the reference birth weight range of 2,500 to 4,000g with accuracy (mean absolute percentage error) of $6.6 \pm 7.4 \%$ depending on gestational age and that below $2500 \mathrm{gm}$ accuracy of the clinical method deteriorates markedly with a mean absolute error of $11.7 \pm 9 \% .^{7,8}$ By contrast, the mean absolute percentage error reflects the variability noted regardless of their direction and, as such, is a much more accurate predictor of differences from actual birthweight. Hence, for practical clinical purposes, the variation between predicted birth-weight and actual birthweight is best expressed in the form of mean absolute percentage error. ${ }^{8}$

A prospective study was conducted at obstetrics and gynecology Department, tertiary care hospital, Mumbai between March 2016 to November 2016, to compare the accuracy of clinical and ultrasonographic estimation of fetal weight at term with actual birth weight. One hundred pregnant women who fulfilled the inclusion criteria had their fetal weight estimated independently using clinical and ultrasonographic methods.

Following parameters are studied:

\section{Age}

Highest number (46) of pregnant women belonged to 20 to 25 years of age group. Mean age of participants was 25.59 years

\section{Gestational age and parity}

Almost $88.0 \%$ participant's pregnancy have gestational age more than 36 weeks by recent ultrasonography. Mean gestational age was 37.5 weeks. $59 \%$ were multigravida and $41 \%$ were primigravida.

\section{Mode of delivery}

In this study $63 \%$ delivered vaginally and $37 \%$ by LSCS. however, the association between actual birth weight and mode of delivery found to be insignificant.

\section{Risk factors}

Actual birth weight found to be influenced by risk factors. Risk factors like hypothyroidism, pre-eclampsia, intra-uterine growth restriction, gestational diabetes mellitus, rheumatoid arthritis, renal failure etc. were present in $23 \%$ cases. The association between actual birth weight and risk factor found to be significant in present study $(\mathrm{p}<0.05)$. This indicate knowledge of the influence of risk factors may contribute to birth weight estimation.

\section{Fundal height and abdominal girth}

Fundal height varied between $26-37 \mathrm{~cm}$, whereas abdominal girth varied between $82-106 \mathrm{~cm}$ among subjects at term gestation. Association of abdominal girth with actual birth weight was also found to be statistically significant in present study. Hence, these parameters need further studies to consider as independent measure for estimating birth weight.

\section{Fetal birth weight estimated by ultra-sonography}

Results shows that $88 \%$ fetus were belonged to birth weight group of 2500 to $4000 \mathrm{~g}$, where $7 \%$ have less than $2500 \mathrm{~g}$ and $5 \%$ have more than $4000 \mathrm{gm}$ birth weight. Mean birth weight measure by USG was $3203.66 \mathrm{~g}$ with 497.05g SD.

The observation that, compared to actual birth-weight, ultrasound overestimated low birthweight and underestimated high birth-weight, has also been previously reported. ${ }^{8}$

Present study reported clinical method was consistent for low birth weight but was inconsistent for high birth weight where ultrasound comparably estimated actual birth weight. 
Interestingly, the mean percentage error can be misleading because it is the sum of positive and negative deviations from actual birth weight, thus artificially reducing the difference between actual birth-weight and estimated birth-weight. It is a measure of systematic error in each method and not variation from birthweight.

With ultrasound, there is an obvious limitation of comparing a spatial measurement with weight. Fetal mass is a function of fetal volume and density, and density of the fetus at term is not constant.8. The major finding from this prospective study is that clinical estimation of fetal weight is as accurate as the ultrasonographic method of estimation within the normal birth-weight range. Moreover, both the clinical and ultrasound method overestimated fetal weight. However, when there is the case of intrauterine growth restriction (birth-weight $<2,500 \mathrm{~g}$ ), both the methods underestimated birth-weight.

\section{Fetal birth weight by clinical examination}

Results shows that $87 \%$ fetal were belonged to birth weight group of 2500 to 4000 grams, where $13 \%$ have less than 2500gram. Mean birth weight measured by clinical examination was 2916.6 gm with $399.15 \mathrm{gm}$ SD.

In 1990, Dare et al, proposed a simpler formula for clinical FWE, which consisted of multiplying SFH by AG. ${ }^{11}$ In their original paper, Dare et al, tested this method on 498full-term patients and obtained a good correlation between the clinical estimate and actual birth weight $(r=0.742)$. In present study also, clinical weight estimation by Dare's method found to have good correlation with actual birth weight. The correlation coefficient between clinical estimate and actual birth weight found to be statistically significant $(r=0.87$, $\mathrm{p}<0.0001$ ) and by ultrasonography it was 0.76 .

\section{Actual birth weight}

Maximum number of neonates had actual birth weight of range $2500-4000 \mathrm{~g}(70 \%)$ followed by $<2500 \mathrm{~g}(25 \%)$ and $>4000 \mathrm{gm}$. The study sample had an actual average birth weight of $2831.79 \pm 515.79 \mathrm{~g}$. Association of fundal height with actual birth weight was found to be statistically significant as also observed in the study by Malik $\mathrm{R}$ et al. ${ }^{12}$ Comparison of actual birth weight by clinical and ultrasonographical weight estimation method. Clinical as well as ultrasonography estimates observed to be strongly correlate with actual birth weight. Both the methods had more sensitivity in birth weight range 2500-4000gm than $<2500 \mathrm{~g}$ and $>4000 \mathrm{~g}$. The overall mean absolute percentage error of the clinical method $(7.2 \pm 7.7)$ was smaller than that of the sonographic method $(16.2 \pm 11.1)$.

In low birth-weight $(<2,500 \mathrm{~g})$ group, mean absolute percentage error was $9.0 \pm 11.3$ with USG and same with clinical was 11.7 \pm 9.0 . No statistically significant difference was observed. But in all the measures of accuracy for the normal birth-weight range of 2,500-
4,000 gm mean absolute percentage error was $16.5 \pm 11.2$ with USG and 6.6 \pm 7.4 using clinical method and difference was statistically significant.

\section{Sensitivity of fetal weight estimation by clinical method and sonography}

Present study showed a clear role of clinical method in estimating fetal weight when compared with ultrasonography. In prediction of the normal range of weight (2500-4000g), Dare's method found to have more sensitivity (97.1\%), than ultrasonography (92.9\%). In estimating fetal weight $<2500 \mathrm{~g}$ by Dare's method it was found that more sensitivity (48\%) when compared with sensitivity of ultrasound $(20 \%)$. Where as in $>4000 \mathrm{~g}$ ultrasound estimation was more sensitive than clinical method. Malik R et al also found, in a study comparing 3 clinical and 3 ultrasonographic equation for predicting fetal birth weight, that in estimating weight $<2500 \mathrm{gm}$ and $>3500$ gram there was a role of ultrasound as additional tool. ${ }^{12}$ Sensitivity and Specificity of ultrasonography formulae were more in $<2500 \mathrm{~g}$ and $>3500 \mathrm{~g}$ as compared to clinical method.

In present study Dare's method showed average mean weight of $2916.6 \pm 399.15 \mathrm{~g}$ which was highly comparable with mean weight of actual birth weight of $2831 \pm$ $515.79 \mathrm{~g}$.

Similar results found in following study:

Table 14: Comparison of fetal weight with other studies.

\begin{tabular}{|l|l|l|l|}
\hline $\begin{array}{l}\text { Mean } \\
\text { weight } \\
\text { (g) }\end{array}$ & Yadav $\mathbf{R}^{13}$ & Ratwani $K^{14}$ & $\begin{array}{l}\text { Present } \\
\text { study }\end{array}$ \\
\hline $\begin{array}{l}\text { Dare's } \\
\text { method }\end{array}$ & $2971 \pm 337.9$ & $2880 \pm 350$ & $2916 \pm 399.15$ \\
\hline USG & $3240 \pm 389.7$ & $2540 \pm 330$ & $3203 \pm 497.05$ \\
\hline Actual & $3100 \pm 455.8$ & $2900 \pm 430$ & $2831 \pm 515.79$ \\
\hline
\end{tabular}

Estimated birth weight between 2500-4000gm was expected $88 \%$ sonologically, $87 \%$ clinically and there was statistically significant difference from actual birth weight, where only $70 \%$ babies had birth weight between 2500-4000gms. Correlation of actual birth weight with clinical and sonography method:

Ugwu et al, observed strong positive correlation of actual birth weight with clinical and ultrasonographic ally estimated birth-weight ( $\mathrm{r}=0.71$ and $\mathrm{r}=0.69$ respectively). ${ }^{15}$ Similar results observed in the study by Njoku C et al, in 2014 as correlation coefficients for the clinical and ultrasonic methods, compared to actual birth weight, were +0.740 and +0.847 , respectively, and both correlated positively with the actual birth weight. ${ }^{16}$ Shittu et al in a study conducted at Southest Nigeria in 2007 found that the correlation coefficient for the clinical and ultrasonic methods, compared to actual birth weight, were observed 
to be +0.78 and +0.74 respectively, the relationships found to be statistically significant $(\mathrm{p}<0.001) .{ }^{17}$ In the study Shittu et al observed that in the low-birth weight $(<2,500 \mathrm{gm})$ group, both the methods systematically overestimated birth weight. ${ }^{17}$ Our correlation coefficient for ultrasound estimation (0.76) is comparable with that of study by Uotila et al, in year 2000, in their comparison of ultrasonic estimation (0.77) with magnetic resonance imaging $(0.95)$ in diabetic and normal pregnancy. ${ }^{18}$

In the middle range of birth weight $(2,500-4,000 \mathrm{gm})$, the clinical method systematically overestimated birth weight. In the high-birth weight $(\geq 4,000 \mathrm{gm})$ group, the clinical method systematically overestimated birth weight, while the ultrasonic method underestimated it. While present study observed that in birth weight <2500gram and 2500-4000gram, Dare's method and ultrasonography overestimated birth weight and for $>4000$ gm, Dare's method underestimated birth weight.

The accuracy of clinical estimation obtained in this study was highest in the birth-weight range of 2,500-4,000gm and lowest for the large-birth-weight group (>4,000gm) as also observed in the comparative study by Kumari A et al. ${ }^{19}$ For the ultrasonographic method, our results are also consistent with what have been previously observed that the mean absolute percentage error of predicted birth weight varies from 5.2 to $27 \%$ of actual birthweight. ${ }^{20}$

Likewise, Baum et al, found no advantage of sonographic estimation over clinical or patients' estimation of fetal weight at term. ${ }^{20}$

The difference from our results may be attributed to the standardized method that was used for clinical estimation in present study. Clinical estimation of birth-weight may be as accurate as routine ultrasonographic estimation, except in high-birth-weight babies. Therefore, when the clinical method suggests weight larger than 4,000gm, subsequent sonographic estimation is recommended to yield a better prediction and to further evaluate the fetal well-being.

Our observation implies that there is clearly a role for clinical estimation of birth-weight as a diagnostic tool, suggesting that clinical estimation is sufficient to manage labor and delivery in a term pregnancy. But ultrasound estimation of weight for macrosomic fetus for making decision regarding trials of labour, is necessary before considering trial.

The role for ultrasonographic fetal weight estimation appears less important in clinically estimated birth weight $<2,500 \mathrm{gm}$, subsequent sonographic estimation may not yield any added advantage in low socioeconomic strata, as actual birth weight is comparable with ultrasound estimation of birth weight. But ultrasound may have added advantage in to reach area which may detect congenital malformation and to do the biophysical profile to determine the well-being of the fetus.
The above findings have important implication for developing countries like ours where there is lack of technologically-advanced ultrasound machines capable of doing sophisticated functions such as fetal weight but has an experienced clinician who could perform this function equally well. Limitations of the study is the subjectivity of clinical estimation, use of only one sonographic model to derive estimates of fetal weight.

\section{CONCLUSION}

Clinical palpation should be considered as diagnostic tool for FWE and is equally reliable even when done by trained medical officer. It is cheap and easy to teach. The need is to practically apply this method in obstetrics and guide the management decisions. Overall, the clinical as well as ultrasound method overestimated birth-weight.

The present study concludes that clinical estimation of birth-weight is as accurate as routine ultrasonographic estimation. We regard the overestimation of fetal weight by the clinical method as a positive factor since it will enhance the sensitivity of health workers at peripheral center if properly taught to them for earlier referral of mothers with macrosomic fetuses, thus contributing to reduction of obstructed labour and its sequelae. When the clinical method suggests weight smaller than 2,500gm, subsequent sonographic estimation is recommended to yield a better prediction such as biophysical profile and to further evaluate fetal wellbeing.

Further studies are, however, necessary to improve the accuracy of fetal weight and to determine if estimation of fetal weight prediction near delivery actually improves outcome.

Funding: No funding sources

Conflict of interest: None declared

Ethical approval: The study was approved by the Institutional Ethics Committee

\section{REFERENCES}

1. Sherman DJ, Arieli S, Tovbin J, Siegel G, Caspi E, Bukovsky IA. A comparison of clinical and ultrasound estimation of fetal weight. Obstet Gynaecol 1998;91:212-7.

2. Chauhan SP, Hendrix NW, Magann EF, Morrison JC, Jenney SP, Devoe LD. Limitations of clinical and sonographic estimates of birth weight: experience with 1034 parturients. Obstet Gynecol 1998;91:72-7.

3. Nzeh DA, Oyawoye O, Adetoro OO. Ultrasound estimation of birth weight in late pregnancy among African women. West African J Ultrasound 2000;1:9-14.

4. Hanretty KP, Neilson JP, Fleming EE. Re-evaluation of clinical estimation of fetal weight: a comparison with ultrasound. J Obstet Gynaecol 1990;10:199201. 
5. Hendrix NW, Grady CS, Chauhan SP. Clinical versus sonographic estimates of birth weight in term of parturients. A randomized clinical trial. J Reprod Med 2000;45:317-22.

6. Raman S, Urquhart R, Yusof M. Clinical versus ultrasound estimation of fetal weight. Aust N Z J Obstet Gynaecol 1992;32:196-9.

7. Watson WJ, Soisson AP, Harlass FE. Estimated weight of the term fetus. Accuracy of ultrasound vs.clinical examination. J Reprod Med 1988;33:36971.

8. Nahum GG, Stanislaw H, Huffakar BJ. Accurate prediction term birth-weight from prospectively measurable maternal characteristics. J Reprod Med 1999;44:705-12.

9. Fasubaa OB, Faleyimu BL, Ogunniyi SO. Perinatal outcome of macrosomic babies. Nig J Med 1991;1:61-2.

10. Mehdizadeh A, Alaghehbandan R, Horsan $H$. Comparison of clinical versus ultrasound estimation of fetal weight. Am J Perinatol 2000;17:233- 6.

11. Dare FO, Ademowore AS, Ifaturoti OO, Nganwuchu A. The value of symphysiofundal height/abdominal girth measurement in predicting fetal weight. Int $\mathbf{J}$ Gynaecol Obstet 1990;31:243-8.

12. Malik R, Thakur P, Agarwal G. Comparison of three clinical and three ultrasonic equations in predicting fetal birth weight. Int J Reprod Contracept Obstet Gynecol. 2016;5(1):210-6.

13. Yadav R, Sharma BK, Deokota RN, Rahman H. Assessment of clinical methods and ultrasound in predicting fetal birth weight in term pregnant women. Int $\mathbf{J}$ Reprod Contracept Obstet Gynecol 2016 August;5(8):2775-9.

14. Ratwani K, Madkar CS, Deshpande HG, Jethani S. Comparative study for estimation of fetal weight by clinical and ultrasonographical methods in term patients. J Evolution Med Dental Sci. 2014;3(10):2553-60.

15. Ugwu E O, Udealor P C, Dim C C, Obi S N, Ozumba B C, Okeke D O, et al. Accuracy of clinical and ultrasound estimation of fetal weight in predicting actual birth weight in Enugu, Southeastern Nigeria. Niger J Clin Pract 2014;17:270-5.

16. Njoku C, Emechebe C, Odusolu P, Abeshi S, Chukwu C, Ekabua J. Determination of accuracy of fetal weight using ultrasound and clinical fetal weight estimations in Calabar South, South Nigeria. Int Scholarly Res Notices. 2014;2014.

17. Shittu AS, Oluwafemi K, Orji EO, Mkinde NO, Ogunniyi SO, Ayoola OO. Clinical versus sonographic estimation of fetal weight in Southwest Nigeria. J Health Popul Nutr. 2007;25:14-23.

18. Uotila J, Dastidar P, Hannone T, Ryymin R, Punonen R, Laasonan E. Magnetic resonance imaging compared to ultrasonography in fetal weight and volume estimation in diabetic and normal pregnancy. Acta Obstet Gynaecol Scand. 2000;79:255-9.

19. Kumari A, Goswami S, Mukherjee P. Comparative study of various methods of fetal weight estimation in term pregnancy. South Asian Feder Obst Gynaecol. 2013;5(1):22-5.

20. Baum JD, Gussman D, Stone P. Clinical and patient estimation of fetal weight vs. ultrasound estimation. J Reprod Med. 2002;47:194-8.

Cite this article as: Ingale A, Khade SA, Shirodkar

S. Clinical versus ultrasonographic fetal weight estimation and its correlation with actual birth weight. Int J Reprod Contracept Obstet Gynecol 2019;8:503-12. 